\title{
About the Mechanism of Ensuring Balance for Attracting Investments for Construction Corporations
}

\author{
Boris Sultanovich Kasaev ${ }^{1} \&$ Azat Ashatovich Razakov ${ }^{2}$ \\ ${ }^{1}$ Professor of the Department of Marketing and Logistics Financial University under the Government of the \\ Russian Federation, Moscow, Russian Federation \\ ${ }^{2}$ Head of construction company "Slavic", Moscow, Russian Federation \\ Correspondence: Boris Sultanovich Kasaev, Department of Marketing and Logistics Financial University under \\ the Government of the Russian Federation, Leningrad Prospect 49, 125993 Moscow, Russian Federation. Tel: \\ 7-905-791-5214. E-mail: bkasaev@mail.ru
}

Received: December 15, 2014 Accepted: December 20, $2014 \quad$ Online Published: April 6, 2015

doi:10.5539/mas.v9n5p219 URL: http://dx.doi.org/10.5539/mas.v9n5p219

\begin{abstract}
The article studies the significant reasons for the lack of balance of the investment support for innovations for construction corporations. Based on a comparison of investment and innovation projects for construction companies, the article notes that an innovative project differs from an investment project with the presence of elevated levels of risk and uncertainty. Some examples show that the estimated financial forecasts turn out to be inaccurate within the course of implementing innovative and investment projects. The main reasons for significant departures from the necessary capital investments realms and the terms of implementing innovative and investment projects beyond common squandering of money are, in fact, arisen from incorrect presentation of works amount, the necessary costs and terms for fulfilling the project, their deliberate understatement for alleviation of investments availability, unfounded changes in the process of the project design performance, inflation faulty assessment, and the underestimation of expenses due to absence of major marketing researches. It is proved that the basic conditions for the effectiveness of projects is the availability of transparent investment mechanism. Another matter of critical importance is the investment mechanism presented with complex of organizational structures, regulatory documents, technologies, human resources, methods, instruments and other necessary means applied for attraction of capital aimed at realization of innovative and investment projects. It is obvious that all the miscalculations linked to the realization of innovative and investment project refer to the low level of preparation and working out of investment mechanism. In the meantime, many factors defining the ability of companies to attract investments are out of possibility of their control. In this context the companies have to perform the organizational activity on design of the affairs they would have overall control over and, subsequently, to influence the sponsors' decisions to invest their capital.
\end{abstract}

Keywords: construction company, the investment mechanism, factors attracting investment, control system investment mechanism, the organization of activities, the level of risk and uncertainty

\section{Introduction}

Among the most important reasons for the lack of balance in investment, support for innovation activities there is the following situation. If we consider the projects separately, we can note that an innovation project differs from investment one with the presence of higher level of risk and uncertainty. In addition, some examples show the estimated financial forecasts turn out to be inaccurate within the course of performance of innovative and investment projects.

To illustrate it we will distinguish some results of error analysis of not very large innovative projects in Great Britain (Aniskin Y. P., 2011) that has shown the required accuracy of estimation of performed investments is being in the range from 100 to $150 \%$, while the accuracy of terms of their performance fluctuates in from 1.4 to 3.1 times. As a rule, it is happened that with increase of both - cost and scales of innovative projects - the error itself grows proportionally.

Thus, for instance, the large-scale construction in Sochi showed that in 2010, when allocating budget funds for Winter Games of Sochi-2014, the expenses made about 350 billion roubles. However, in fact, by the end of 2013, 
the estimation of Olympiad in Sochi in 2014 had already risen beyond 950 billion roubles. At last, according to the estimations of experts, the expenses for Olympics made up $\$ 50$ billion. The expenses for previous Olympics demonstrated that Winter Games in Sochi could become too expensive. The expenses for correspond games of former years made about \$1.5-3 billion. To compare the costs of performance of Sochi games with other equivalent affairs we will list some numbers:

The expenses for Olympics in Turin (1996) - less than $\$ 3,5$ billion;

The expenses for Olympics in Vancouver (2010) - less than $\$ 2$ billion.

To organize the Winter Games in Sochi about $\$ 6.4$ billion were spent. This sum excludes the expenses for infrastructure. Taking into account the budgetary funds allocated for development of infrastructure in Sochi the sum raises to $\$ 50$ billion. In such a manner, the expenses for Olympics in Sochi are 14.2 times more than in Turing and 25 times more than in Vancouver.

The main reasons for significant departures from the necessary capital investments realms and the terms of implementing innovative and investment projects beyond common squandering of money are, in fact, arisen from incorrect presentation of works amount, the necessary costs and terms for fulfilling the project, their deliberate understatement for alleviation of investments availability, unfounded changes in the process of the project design performance, inflation faulty assessment, and the underestimation of expenses due to absence of major marketing researches.

Another matter of critical importance is the investment mechanism presented with complex of organizational structures, regulatory documents, technologies, human resources, methods, instruments and other necessary means applied for attraction of capital aimed at realization of innovative and investment projects.

It is obvious that all the miscalculations linked to the realization of innovative and investment project refer to the low level of preparation and working out of investment mechanism.

In the meantime, many factors defining the ability of companies to attract investments are out of possibility of their control.

In this context the companies have to perform the organizational activity on design of the affairs they would have overall control over and, subsequently, to influence the sponsors' decisions to invest their capital.

In the investment sphere among the factors characterizing development of crisis there are:

- The lack of economic and administrative responsibility for the results of investment decisions and ineffective use of capital;

- Rather high cost of attracted capital;

- Reduction in scientific and technical potential of leading branches of economy.

\section{Materials and Methods}

The structural blocks and the elements of content of organizational mechanism for attraction of investments to construction companies are illustrated in Figure 1.

Concerning the innovative projects there is definite necessity to consider the investment project in the matters of its sustainability.

In the present case, the project sustainability is presented with its financial and economic performance that guarantees fulfilment of liabilities to investors and other participators of the project.

The latter is being possible in the case of adequacy of return from realization of innovative and investment project and, correspondingly, of incomes and expense.

The check of sustainability can also imply development of scenarios for realization of project. 


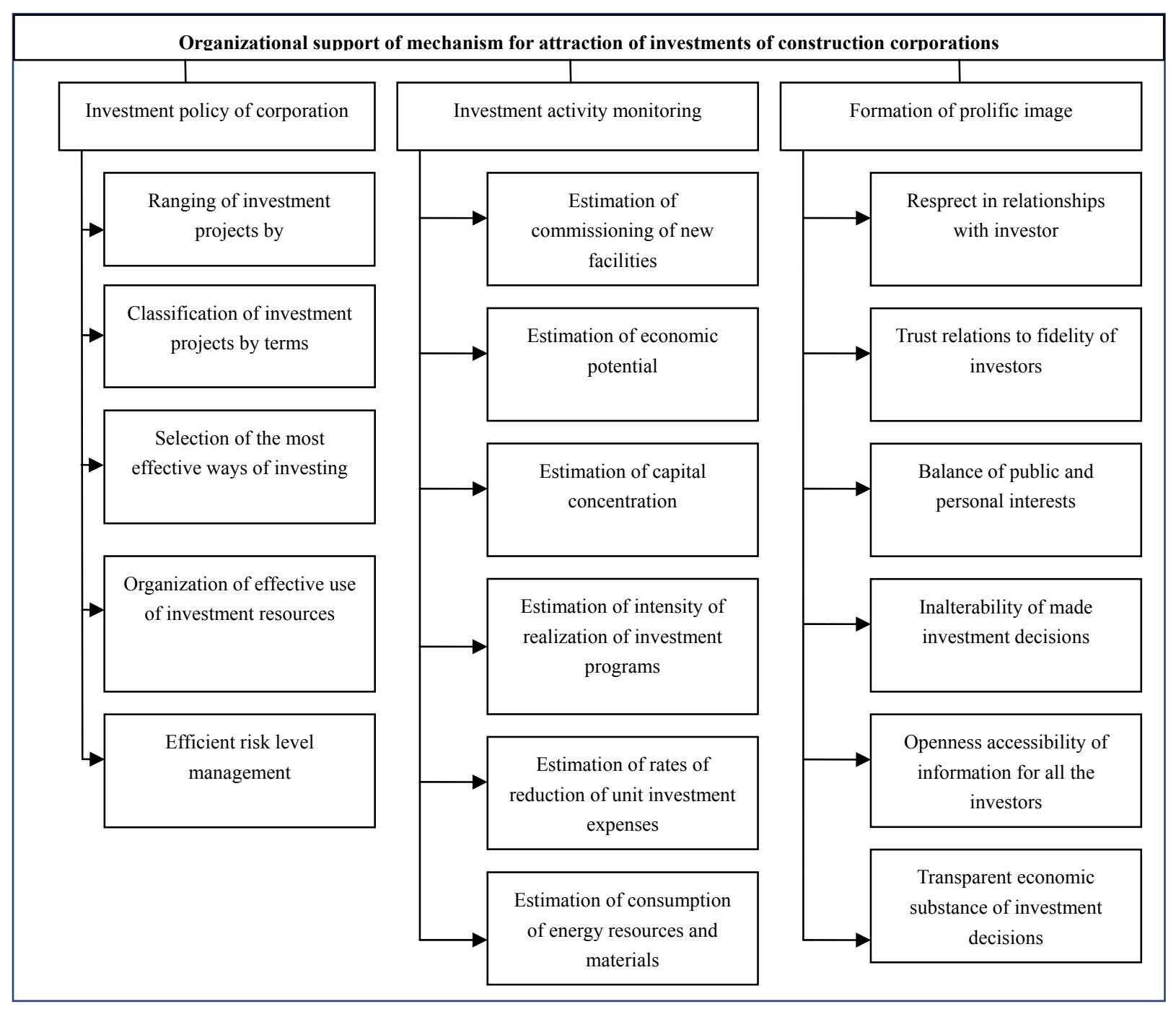

Figure 1. The structure of organizational support of investment mechanism of construction corporation

The content of component - the organizational structure - is illustrated in Figure 1.

The main components are investment policy of company, investment activity monitoring system and methods for formation of prolific image.

The investment mechanism of construction corporation (Figure 2) is being the complex of:

- Organizational structures,

- Regulatory documents,

- Technology,

- Human resources,

- Methods, instruments,

- Reconciliation procedures and necessary resources applied for the purposes of attraction of capital aimed at the realization of investment projects. 


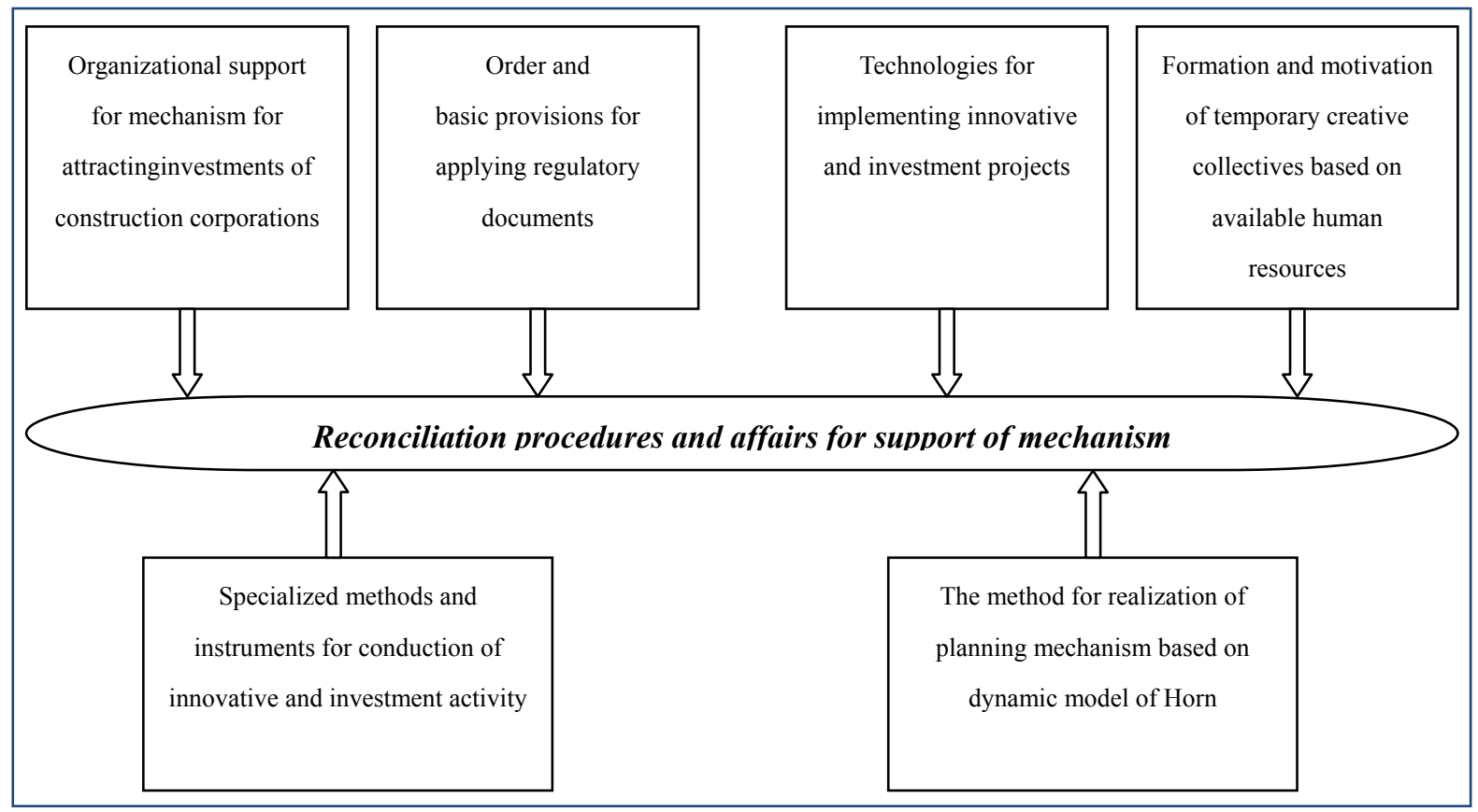

Figure 2. The structure of main blocks of investment mechanism of construction corporation

As far as the development of corporation is defined with objective necessity for growth and planning of processes in different states of balance, the investment mechanism can include the model of achievable growth by Van Horn (Van Horn, J. K., 2003). that has the following from:

$$
S G R=\frac{\left(E q_{0}+N e w E q-I\right)(1+D / E q)(Q / A)\left(1 / Q_{0}\right)}{1-[(P R / Q)(1+D / E q)(Q / A)]}-1
$$

where:

$\mathrm{Q}_{0}$ - initial volume of production (sales);

$\mathrm{Q}$ - planned volume of production (sales);

$\mathrm{Eq} 0$ - initial stock of equity capital;

NewEq - volume of attracted new equity capital;

I - yearly amount of dividends the company is ready to pay (or interests on credits and loans);

A - total value of assets;

D - value of debt capital;

PR - net profit.

The model of Higgins (Higgins, R. C., 1975) provides an idea of critical variables (net profit ratio, profit capitalization ratio, financial leverage ratio, asset turnover ratio) defining the stable growth of a company.

However, the considered model of Higgins implies that basis variant remains unchanged and only separate parameters range, i.e. the company functions under the conditions of some stability and the stability of markets, what in the current context raises doubts - especially for construction companies. The current situation is that the external environment (together with firms) changes very quickly and this is being quite an important fact for the character of construction industry to consider. That is why one should be guided by dynamic models of growth.

In comparison to the models of Higgins describing the static of processes of planning of persistent growth, the dynamic model of Van Horn in its initial variant (Van Horn, J. K., 2003) allows providing solutions for the following list of scientific and administrative problems:

- Definition of achievable rates of economic growth;

- Definition of interrelation and influence of used indicators;

- Simulation of rates of achievable growth. 
Under the conditions of unbalance and, as a rule, with due consideration of demands made by external environment of company, there is necessity for additional transformations that could provide solution either of other specific tasks of research within the considered problem:

- Estimation of the level of interrelation between production and innovative potential of company for the purpose of analysis of possibilities of growth under the present volume of investments;

- Identification of major conditions, limitations and key characteristics of processes necessary for provision of work of investment mechanism based on the model of Van Horn (Van Horn, J. K., 2003);

- Identification of priority economic ratio of nomenclature planned for production;

- Regulation and controlling of production and innovative and investment activity;

- Planning of economic growth on the basis of set master values on set indicators of company;

- Identification of the plan for balanced growth of making innovative production on the basis of master values of key indicators of company;

- Substantiation of economic effect due to the realization of method of balanced planning.

\section{Results and Discussion}

The company's realization of necessary level of investment management, increase of its innovative and investment attractiveness and efficiency in the framework of the structure of temporary creative collective (TCC) imply:

- Company's generation of reference structure of investment management based on the idea of risk-management as the part of overall management system of company;

- Applying of policy for increase of company's attractiveness in full and its business segments in particular implying provision of required quality of corporate management, increase of its resource potential, improvement of quality of innovative and investment programs;

- Creation and implementation of Corporate Code of Conduct for the purpose of increase of business-culture within different segments of business;

- Identification and subsequent improvement of instruments for formation of prolific image of company;

- Formation and stabilization of company's marketing activities;

- Approbation of scientific research results by means of participation in conferences dedicated to financial markets and investments on world, Russian and regional levels, development of relations with potential investors, representatives of international financial organizations, leading analysts and experts of financial market, participation in non-commercial organizations, unions, sectorial and construction associations;

- Development of methods for effective informational and technological management, implementation of modern automated process control systems and systems for quality management, ecology and labour protection meeting international standards and witnessing high managerial, production and common culture of companies of world level.

On the other part the availability of developed methods and instruments for conduction of innovative and investment activity implies:

1) In the part of increase of the level of investment from own funds:

- Increase and stabilization of processes of use of company's own funds for the investment purposes (increase of net profit, amortization expenses, reinvested part of non-current assets and immobilized part of current assets), creation of specific development funds due to vacant sources for the purpose of formation of company's reserves;

- Calculation and optimization of settlement structure on the basis of provision of effective receivables management with use of modern factoring instruments;

- Development of system budgeting principles and other instruments for improvement of financial discipline.

The sound technical and economic policy of investments into development of innovations will promote the company's adaptation to the dynamic of processes of market economy. The company's business-segments in market economy should be guided not by approximate plan tasks, but by marketing results of researches, including demand, competition, and costs - for these factors will further define the efficiency of company.

In such a situation, it is possible to reach safe position on the market only by means of rehabilitation of 
production funds, modernization of technological processes structure and further development of technical and economic level of production.

To perform this company should not make financial problems, since the realization of projects for technical re-equipment of technological processes should be provided with volume of financial means, as the reduction in production efficiency has already become the factor of regression and adequate profit shrinkage.

Numerous studies show that minimal volume of investments into constant updating of production potential (for the purpose its average age to remain at the level of 6-7 years), according to various estimations of experts, should succeed the current level in 5-6 times.

2) In the part of activation of investment flows with use of Russian and foreign financial markets:

- To perform the estimation of opportunities for use of new instruments of financial market for increase of investment flow, management of risks and long-term liabilities, i.a. of ones approved in international practice;

- To adopt measures for increase of company's capital stock for significant improvement of capitalization and further growth of investment attractiveness;

- Increase of rates of organization of activity on company's business debt programs formation: in particular, the formation of resources on the basis of bonds on internal and external markets (by emission of corporate bonds that gives opportunities of applying cheaper and long-term loans and creating conditions for formation of international credit rating); organization of issuing of convertible bonds;

- Preliminary settlement of ways for launch of successful company's projects to foreign markets (by use of method of global depository receipts) for the purpose of geographic expansion of end market and additional attraction of investors;

- $\quad$ Enhancement of processes of realization of methods for initial public offering (IPO).

3) As to development of use of financial resources of credit investment system on the territories of state and regions:

- To provide the necessary level of correlation of the investment capital structure with sources of financing in accordance with prospect strategy for company's development;

- Development of consortium loans' system (with participation of several banks) for large-scale investment projects promoting allocation of risks and insurance of investment and credit risks;

- To develop credit provision on short-term and long-term basis upon the security of promissory notes and other securities;

- To provide attraction of necessary credit structures for financing of innovative and investment projects' portfolio and, subsequently, to diversify risks according to the proportional volume of investment income.

- To work out the mechanisms of modern leasing schemes for financing upon purchase (i.a. of specific equipment);

- To research possibilities for attraction of finance of various funds (i.a. of pension funds) and other structures of investment market.

4) In the part of development of prospect for attraction of foreign investments:

- To work out the conditions for credit provision on the part of foreign investment institutions with further use of such financing strategies as organization of credit lines on the security of foreign banks performed when defining initial deposit; organization of credit line in exchange for forward contract for delivery of products;

- To develop variants of joint enterprises - attraction of foreign investments to the structure of own capital;

- $\quad$ To research the potential of foreign direct investment fund;

- To estimate the possibility of foreign investments in the form of debt capital (since the main advantage of this method consists in offset of payments on loans upon defining of taxable income, while payments of dividends are performed by net profit).

5) The situation demanding for creation in company of instruments for risks and debt liability management:

- Implementation of systems for debt liability management and use of instruments for debt management (factoring, debt currency change, increase of terms of debt servicing, etc.); 
- Activation of methods for risk management (diversification of investment risks - improvement of investment assets and financing sources management; their optimization on directions, volumes, terms and structure);

- Creation of necessary reserves used at realization of risks; delivery of risks to specialized credit and financial institutions - the insurance companies;

- Development of sound instruments for insurance in the process of realization of investment strategy: insurance of non-current assets (includes risks of physical damage and losses and risk of business liquidation; the responsibility in such a case can be public, product and personnel); insurance of political risk; insurance of new projects (all the risks contractors and risks of subsequent losses, assembling risks); insurance of goods transportation; credit insurance;

- Increase of rates of improvement and structuring of use of financial guarantees system.

In the frameworks of "investment policy" block, the most effective use of investment resources is provided with performance of number of affairs: ranging of investment projects; classification of investment projects in terms; selection of the most effective ways of investing; organization of effective use of investment resources; effective risk levels management.

The main task on credit resources is the identification of payments flows providing redemption of loan debt. To solve the task there first the following massifs should be formed:

- $\quad$ Amounts of credit (the current amount of long-term liabilities $-S k z[i]$ );

- Amounts of interest payment for credit accommodation that are not subject to tax $(P k r[i])$;

- $\quad$ Amounts of back payments ( $\mathrm{Svz}[i])$;

The massif of credit amount in the stages of account period is formed on basis of massifs of amount and terms for obtaining of credit from "Capital construction" block. For this purpose by the end of each stage within the period of construction, the amount of credit received before putting the object into operation is defined with accrued method. Part of the massif of credit amount for account period of object's operation is formed under the conditions of contract for credit redemption. In the contract, the procedure for credit redemption and back payment is specified.

Usually the credit can be repaid with equal amounts in the end of every half-year or year of account period of object's operation. In such a case, the size of outpayments for credit redemption $(S v)$ in the end of each stage of operation period can be defined in the following way:

$$
S v=\frac{K r n[t s]}{N v},
$$

where: $K r n$ - the total amount of loan, obtained for construction of object, with use of accrued method;

ts - number of stage of completion of object's construction;

$N v$ - amount of payments.

Then, concerning the operation period the massif of credit amount $(S k z)$ is defined with the following ratios:

$$
\begin{gathered}
S k z[t s]=K r n[t s], \\
S k z[i]=S k z[i-1]-S v,
\end{gathered}
$$

where: $i$ - is changed within the limits from $i=t s+1$ to $i=t r, t r$ - the duration of account period.

If the rate of interest on credit does not exceed the value that is not subject to tax, the massif of payment of interest on credit $(P k r)$ is formed with help of the following equation:

$$
P k r[i]=P k \cdot K r n[i] \quad(\text { for } i \text { from } 1 \text { to } t s \text { ). }
$$

Regarding the present part of massif, the cost of production capital funds should be increased.

For the period of operation of object:

where: $P k$ - the interest rate for credit accommodation.

$$
\operatorname{Pkr}[i]=P k \cdot S k z[i-1] \quad(\text { for } i \text { from } t s+1 \text { to } t r)
$$

The massif of amounts of accumulated interest for credit accommodation $(\mathrm{Spr})$ is defined within the period of object's construction for the first stage with help of the following ratio: 


$$
\operatorname{Spr}[i]=\operatorname{Pkr}[i],
$$

And for all the subsequent ones - within the period of construction:

$$
\operatorname{Spr}[i]=\operatorname{Pk} \cdot(\operatorname{Spr}[i-1]+\operatorname{Krn}[i])
$$

and by formula:

$$
\operatorname{Spr}[t s+1]=\operatorname{Pk} \cdot \operatorname{Spr}[t s]
$$

As for the first stage of object's operation.

If the stage of payment is less than set term for interest accrual and being a multiple of it, instead of $P k$ value we should use its corresponding part - dpk calculated with help of ratio for transition of simple interest to compound one:

$$
d p k=\frac{\exp \left\{\frac{\ln (1+P k)}{R v}\right\}}{P k}
$$

where: $\mathrm{Rv}$ - the ratio of term for interest payment to the stage of payment.

In case of obtaining credit at random moment of the stage the amount of debt for it is calculated with multiplication of interest rate value ( $P k$ or $d p k$ ) by the period of interest accrual.

In accordance with contract for credit accommodation, the credit redemption can be provided at the end of the first stage of object's operation. Then the amount of debt to pay is defined in the following way:

$$
\begin{gathered}
S v z[t s+1]=S p r[t s+1]-P k r[t s+1]+S v, \\
S v z[i]=S v \text { (for } i \text { from } t s+2 \text { to } t r),
\end{gathered}
$$

The massif of amounts of payments for credit redemption calculated in such a way is used as the part of current liabilities of analytical accounting and paid from net profit.

When evaluating investment attraction of innovative and investment projects, there can be definite situations requiring some changes in making calculations:

1. The amount of debt defined by the moment of putting object into operation (for 2-3 years of construction of large complex) cannot be paid at the end of the first stage of object's operation.

2. Parts of credit provided in different periods of construction are considered as independent.

3. The amount of credits at the last stage of object's construction is increased for purchase of raw products, materials, and component parts.

\section{Conclusion}

In such a way, in the process of creation of mechanism of balanced planning one should take into account the fact that the key features of organization and management under conditions of focusing at science-intensive means of production for construction corporation are (Van Horn, J. K., 2003). :

- The system character of organization of all the company's activities requiring solution of number of problems on creation of innovations: from scientific researches and development works to serial production and operation;

- Orientation of target set of researches, developments and production to peculiar result with prospect directions of works of system-wide and fundamental destination;

- Increased scientific and technical level of output product;

- Significant share of expenses for scientific and research and development works;

- Preponderance of the process of technology change over stationary production and related necessity for regular updating of production funds and development of experimental base;

- Diversified character of researches and developments, as well as the diversity and multinomenclature of production;

- Increased dynamism of production development manifesting itself in constant updating of its elements (subjects of researches, developments and production, technology, schematic and structural solutions, informational flows, etc.), change of quantitative and qualitative indicators, what complicates the task of 
balanced load and use of production potential;

- Multilevel intra- and interbranch cooperation caused with the complexity of science-intensive production and specialization of enterprises and organizations;

- Increase of uncertainty (entropy) in management of up-to-date developments requiring use of prognosis evaluation of future technologies. Creation of brand new products is, as a rule, performed in parallel with development of main components (schematic and structural solutions, physical principles, technologies, etc.). Compliance with necessary values of technical and economic parameters of new production is characterized with high degree of scientific and technical risk. The justified risk in creation of new components of system can define the strategy based on exploratory researches in fundamental and applied areas of science and technology on the basis of development of alternative variants of the components. Here we should also consider that the present strategy can lead either to increase of expenses, practicability of which is not always justified;

- Activation of investment process presented with the most important factor for achievement of goals of researches and development of high scientific and technical level that accompanies realization of big projects;

- Formation of creative collectives with major share of scientists, highly experienced engineering and technical workers and production-industrial personnel in total amount of workers dealing with developments and production.

The possible prospect for further researches on the matter of increase of effectiveness of innovative and investment activity of construction corporations includes, to our opinion, two principal instruments: the first one is related to realization of accounting of territorial aspect of corporation's business-segments, in consequence of which there is necessity for use of methods for marketing of territories; the second one is related to affairs on provision of balanced system of characteristics (Kaplan, R. S., 1996). (BSC), in consequence of which there is necessity for research of possibilities of method of balanced system of characteristics with due consideration of features of their realization for construction corporate structures.

\section{References}

Aniskin, Y. P. et al. (2007). Corporate management of innovative development. Moscow: Omega-L, 411.

Higgins, R. C. (1977). How much growth can a firm afford? Financial Management, 6(3), 7-16.

Investment and construction projects management: International approach, guidance under the editorship of Mazura I.I. - Moscow: Omega-L, 2010, 736.

Kaplan, R. S. (1996). The Balanced Scorecard: Translating Strategy into Action. Kaplan R.S., Norton D.P. Boston (Ma., USA): Harvard Business School Press.

Van Horn, J. K. (2003). The basics of financial management. Moscow: Finances and statistics, 800.

\section{Copyrights}

Copyright for this article is retained by the author(s), with first publication rights granted to the journal.

This is an open-access article distributed under the terms and conditions of the Creative Commons Attribution license (http://creativecommons.org/licenses/by/3.0/). 